\title{
Validity and Reliability of Turkish Version the Family Inventory of Needs-Pediatric II: An Inventory to Identify Care Needs of Parents of Children with Cancer
}

\author{
(D) Handan BOZTEPE,' (1) Ayşe AY, ${ }^{2}$ (D) Leanne MONTEROSSO3 \\ 'Department of Nursing, Faculty of Health Sciences, Atılım University, Ankara-Turkey \\ ${ }^{2}$ Department of Pediatric Nursing, Hacettepe University, Ankara-Turkey \\ ${ }^{3}$ University of Notre Dame Australia, School of Nursing and Midwifery, Murdoch-Australia
}

\begin{abstract}
OBJECTIVE
This study was conducted to translate and adapt the Family Inventory of Needs-Pediatric II (FIN-PED II) into the Turkish language and investigate its validity and reliability for parents of children with cancer.

\section{METHODS}

A self-administered questionnaire and Family Inventory of Needs-Pediatric II was completed by 180 parents whose children (0-18 years old) were diagnosed with leukemia, solid tumors, and central nervous system tumors. FIN-PED II was translated into Turkish and then back-translated and then evaluated by three experts for face validity. For construct validity, exploratory factor analysis was applied and for reliability, internal consistency analysis was employed.
\end{abstract}

\section{RESULTS}

As a result of exploratory factor analysis, it was observed that percentages of explaining total variance were $74.787 \%, 68.649 \%$, and $72.746 \%$ for sections of the importance of care needs, the need fulfilment, and the need for further information, respectively. As a result of Cronbach's Alpha reliability analysis, the reliabilities of the sections on the importance of care needs, need fulfilment, and the need for further information for FIN-PED II was $0.814,0.906$, and 0.915 .

\section{CONCLUSION}

Although the Turkish version of FIN-PED II needs further psychometric testing, it is an effective, valid and reliable tool to find out the care needs of parents of children with cancer.

Keywords: Care needs; parents; pediatric cancers; reliability; validity.

Copyright $\odot$ 2019, Turkish Society for Radiation Oncology

\section{Introduction}

The incidence of childhood cancer varies between 110 and 150 in a million for children under 15 years old. Every year, approximately 7600 children are diagnosed with cancer in the United States of America.[1] With reference to Pediatric Cancer records of Turkish Pe- diatric Oncology Group (TPOG) and Turkish Society of Pediatric Hematology (TSPH) in 2002-2009, 11.898 children were diagnosed, leukemia was on the first rank with the rate of $32.4 \%$, lymphomas was on the second rank with the rate of $16.8 \%$, and central nervous system tumor was on the third rank with the rate of $13.2 \%$ among these diagnoses.[2] 
Having a child with cancer is a very difficult experience for parents. Parents attempting to manage the increasing treatment burden of the child and the side effects caused by cancer treatments completely focus on the needs of the sick child generally by deferring their own needs.[3,4] Parents undertake the tasks of learning complicated treatment protocols, following up on chemotherapy and its side effects, maintaining efficient contact with healthcare personnel, and providing support to other members of the family, in addition to the sick child. Parents might also experience problems in their relationships with their sick children, affecting family experiences with other children and spouses. $[4,5]$ During this process, parents require information, guidance, and support to facilitate decision making.[6]

It is important and essential for healthcare professionals to determine, meet, and follow up with the needs of parents in the early period for the purpose of preventing these psychological and psycho-social problems. [7] In the literature, it has been observed that the needs of parents of children with cancer involve the need for information, physical and emotional needs, practical needs, and the need for financial support. [6,8] Parents need their questions to be answered, to know about the procedures administered and have knowledge about when expected side effects will occur. $[9,10]$ Monterosso (2008) stated that the information needs of parents of children with cancer were not met at a rate of $30-50 \%$. [8] A review of the Turkish literature failed to show any studies undertaken to identify the met and unmet needs of parents of children diagnosed with cancer. Further, an assessment instrument that could be used for this purpose was not available. We undertook the translation of the English version of the Family Inventory of Needs-Pediatric II questionnaire[11] into Turkish, and then established the validity and reliability of the revised instrument. This study aimed to adapt to the Family Inventory of Needs-Pediatric II (FIN-PED II) into the Turkish language and investigate its validity and reliability for parents of children with cancer.

\section{Materials and Methods}

\section{Sample and Setting}

A descriptive cross-sectional study was conducted to adapt the Family Inventory of Needs-Pediatric II (FINPED II) into the Turkish language and investigate its validity and reliability to determine the needs of parents of children with cancer. The population of this study consisted of parents of children in the age group of 0-18 years old, followed up with diagnoses of leukemia, solid tumor, or central nervous system tumor between February 2015 and June 2015 in the pediatric hematology and oncology unit and outpatient clinics of Hacettepe University İhsan Doğramacı Children's Hospital and Hacettepe University Oncology Hospital. This study was conducted with 180 parents (leukemia $[n=60]$, solid tumor $[n=60]$ and central nervous system tumor $[\mathrm{n}=60]$ ) who agreed to participate in this study and were older than 18 years old. Parents who had no communication problems, whose children were followed up with diagnoses of leukemia, solid tumors, or central nervous system tumors, and who agreed to participate in this study were included.

\section{Parent and Child Form}

In this study, the data were collected using a data collection form based on the relevant literature. $[8,9,11,12]$ This form involved variables, such as the parents' ages, educational backgrounds, occupations, cohabitation status, economic status, number of children, and places of residence, as well as the age, gender, and diagnosis of the ill child, the type of treatment, and the frequency of hospitalization. The questionnaire and the inventory were applied to the participants by the researchers using face-to-face interview methods. Interviews with the parents were conducted at times when they were convenient and willing. A researcher (A.A) briefly informed the participants about the questionnaire and the inventory and explained to them how to complete the forms.

\section{Family Inventory of Needs-Pediatric II}

This instrument was developed by Monterosso (2006). The scale consists of 17 items and includes three rating scales: "the importance of care needs", "met needs" and "the need for further information". The first rating scale of the scale measures the importance level of care needs with a score ranging from 0 (not at all important) to 4 (extremely important). The second measures the degree of the met needs, and similarly, each item has a score ranging from 0 (not met at all) to 4 (completely met). The last evaluates the status of further information, with a score ranging from 0 (no further information is required) to 4 (a great deal of information is still needed). Scores obtained from the inventory ranged between 0 and 68 . Validity and reliability studies of the inventory were conducted in 85 parents of children who were in the age group of 0-19 years old and were diagnosed with solid tumors and leukemia. The internal consistency of the rating scale 
"Importance of Care Needs" was 0.83, the internal consistency of the rating scale "Met Needs" was 0.90 , and the internal consistency of the rating scale "The Need for Further Information" was 0.98.[11]

\section{Analysis}

Analyses were completed by transferring the data into the IBM SPSS Statistics software program, version 22 . The number and percentage distributions were used for the socio-demographic characteristics of the parents and children. The level of significance was accepted $p<0.05$. When testing the validity of the inventory, exploratory factor analysis was applied, and Cronbach's Alpha coefficient was calculated for reliability analysis upon valid results of the inventory. Linguistic equivalence study was conducted to adapt the "Family Inventory of Needs-Pediatric II", used in this study, into Turkish. Within the scope of linguistic equivalence study, support was received from an academic member, who was specialized in the nursing field and had language competency, and two linguists for translation of the inventory from English into Turkish. Translation appropriate for each item was determined by comparing three scales to be translated into Turkish. The inventory, which was assessed for Turkish compatibility, was translated from Turkish into English by three linguists. The inventory translated back into English was compared with original inventory to determine if there was any semantic change in statements and the Turkish version of the inventory was finalized following the comparison.

\section{Ethical Considerations}

Permission was obtained from the author to conduct a validity and reliability study of the inventory in Turkey via e-mail. The Author sent the inventory via an e-mail to researchers. Ethics committee approval was received from the Non-invasive Ethics Committee of Hacettepe University (GO 15/151-10), and the permission was obtained to conduct the study from hospitals. Written consent was obtained from each participant included in this study.

\section{Results}

Table 1 shows some characteristics of the parents and their children. $72.8 \%(n=131)$ of the parents were women, the majority of them $(n=52,28.9 \%)$ were in the age range of 31-35 years and graduated from high school/university $(\mathrm{n}=85,47.2 \%)$. In this study, $74.4 \%$ $(n=134)$ of the parents were unemployed, and they

\begin{tabular}{|c|c|c|c|}
\hline \multirow[t]{2}{*}{ Table 1} & \multicolumn{3}{|c|}{$\begin{array}{l}\text { Demographic characteristics of parents and } \\
\text { children }\end{array}$} \\
\hline & & $\mathbf{n}$ & $\%$ \\
\hline \multicolumn{4}{|l|}{ Gender } \\
\hline Fem & & 131 & 72.8 \\
\hline Male & & 49 & 27.2 \\
\hline \multicolumn{4}{|l|}{ Age } \\
\hline $30 \mathrm{Ye}$ & rs and below & 38 & 21.1 \\
\hline $31-3$ & Years & 52 & 28.9 \\
\hline $36-4$ & Years & 44 & 24.4 \\
\hline $41 \mathrm{Ye}$ & rs and above & 46 & 25.6 \\
\hline \multicolumn{4}{|c|}{ Number of Children } \\
\hline 1 & & 30 & 16.7 \\
\hline 2 & & 67 & 37.2 \\
\hline 3 & & 48 & 26.7 \\
\hline 4 anc & above & 35 & 19.4 \\
\hline \multicolumn{4}{|c|}{ Place of Residence } \\
\hline City & entre & 134 & 74.4 \\
\hline Cour & ry Centre and Village & 46 & 25.6 \\
\hline \multicolumn{4}{|c|}{ Social status } \\
\hline Marr & & 174 & 96.7 \\
\hline Divo & & 2 & 1.1 \\
\hline Sing & Parent & 4 & 2.2 \\
\hline
\end{tabular}

Demographic Characteristics of Parents and Children (continuous)

$\begin{array}{lcc}\text { Education Level } & & \\ \quad \text { Illiterate } & 11 & 6.1 \\ \quad \text { Primary/Secondary School } & 84 & 46.7 \\ \quad \text { High School/University } & 85 & 47.2 \\ \text { Financial status } & & \\ \quad \text { Poor } & 54 & 30.0 \\ \quad \text { Mean } & 98 & 54.4 \\ \quad \text { Good } & 28 & 15.6 \\ \text { Gender (Children) } & & \\ \quad \text { Girl } & 69 & 38.3 \\ \quad \text { Boy } & 111 & 61.7 \\ \text { Diagnosis } & & \\ \quad \text { Leukaemia (ALL/AML) } & 60 & 33.3 \\ \quad \text { Solid Tumors } & 60 & 33.3 \\ \quad \text { Central Nervous System Tumors } & 60 & 33.3 \\ \text { Age (Children) } & & \\ \quad \text { 3 and above } & 41 & 22.8 \\ \text { 4-9 } & 82 & 45.6 \\ \quad \text { 10-19 } & 57 & 31.7 \\ \text { Type of treatment } & & \\ \quad \text { Chemotherapy } & 152 & 84.4 \\ \quad \text { Radiotherapy } & 15 & 8.3\end{array}$

Demographic characteristics of parents and children (continuous)

\begin{tabular}{lcc}
\hline Bone marrow transplantation & 12 & 6.7 \\
$\quad$ Surgery & 21 & 11.7 \\
Time from patient diagnosis & & \\
$\quad 1$ year and below & 120 & 66.7 \\
1 Year above & 60 & 33.3 \\
$\begin{array}{l}\text { Number of hospilitazion } \\
\text { Outpatient }\end{array}$ & 3 & \\
1-5 times & 91 & 50.6 \\
5 times above & 86 & 47.8 \\
\hline
\end{tabular}


$(\mathrm{n}=98,54.4 \%)$ described their economic status as moderate. $61.7 \%(n=111)$ of the children with cancer included in this study were boys. When the age distribution of the children was examined, it was observed that there were $22.8 \%$ of the children three years old and younger, $45.6 \%$ were aged between $4-9$ years, and $31.7 \%$ were aged between 10-19 years. Most of the children received chemotherapy $(\mathrm{n}=152,84.4 \%)$ and were diagnosed one year before or in a shorter time $(n=120,66.7 \%)$.

\section{Construct Validity (Exploratory Factor Analysis) for FIN-PED and Internal Consistency of the Inventory (Cronbach's Alpha)}

Exploratory factor analysis was used to test the construct validity of the FIN-PED, consisting of 17 items over 180 parents. Accordingly, as a result of the KMO test, 180 parents were determined to be sufficient to test construct validity for sections importance, the need fulfillment, and the need for further information $(\mathrm{KMO}>0.50)$. As a result of Bartlett's Test of Sphericity, results of exploratory factor analysis were observed to be useable for sections of importance, the need fulfillment, and the need for further information $(\mathrm{p}<0.05)$.

As a result of exploratory factor analysis, it was observed that percentages of explaining total variance were $74.787 \%, 68.649 \%$, and $72.746 \%$ for sections of importance, the need fulfillment, and the need for further information, respectively. Percentages of explaining total variance were at a very high level $(>\% 50)$. Accordingly, it was observed that 17 questions used for sections of importance, the need fulfillment, and the need for further information were in coherence and they had high levels of correlation between them. Consequently, the construct validity of FIN-PED was ensured.

Table 2 shows Cronbach's Alpha of FIN-PED II. As a result of Cronbach's Alpha reliability analysis, reliabilities of sections of importance, the need fulfillment, and the need for further information for FIN-PED were observed as $0.814,0.906$, and 0.915 , respectively. Accordingly, these sections were highly reliable. The internal consistency of FIN-PED was ensured.

Table 2 Cronbach's alpha of FIN-PED II

\begin{tabular}{lc} 
Three rating scales & Cronbach's Alpha \\
\hline The importance of care needs & 0.814 \\
The need fulfilment & 0.906 \\
The need for further information & 0.915 \\
Total scale & 0.875 \\
\hline
\end{tabular}

\section{Discussion}

This study supports FIN-PED II as an effective tool for measuring of the care needs of parents of children with cancer as well as established studies about the reliability and content validity of FIN-PED II.[9,11,13,14] This study provided a tool about the needs of parents of children with cancer, which is a topic that has not previously been studied in Turkey. The met and unmet needs of the parents can be determined by studying the validity and reliability of a recent version of FIN-PED II. Initial psychometric testing of the Turkish version of the FIN-PED II showed significant results as well as each of its subscales. Internal consistencies were found in this study $(.81, .90$, and .91$)$ were similar to other studies (.83, .90, and .98 in Monterosso et al., 2006 [11]; .94 for the both subscales obtained Whiteley et al., 1999 [14]; .84, .90, and .89 in Arabiat and Altamimi 2013 [9]; $.84, .91$ and .88 in Arabiat et al., 2015).

It was determined in the present study that the needs of the parents of children with cancer to know about the treatment, side effects, prognoses, and how to provide care to their child at home and to be informed by healthcare personnel in understandable language and the needs of child to ask questions easily were most important. Previous studies have revealed that parents had the need for information about the diagnosis of their child and his or her treatment, diagnostic procedures, and coping with treatment processes expected side effects, prognosis, and daily care. [15-17] Within this context, the present study supported the results from the literature. It is important to evaluate the needs of parents, to maintain the treatment regime of the child, to realize the clinical picture, which might go unnoticed, to become involved in the child's medical care, and to decide concerning preventing the results that can cause parents to experience emotional, social and financial difficulties.[18]

The Turkish version of FIN-PED II represents the first step to developing a clinically efficient tool to identify the care needs of parents of children with cancer in Turkey. The second step of this process can be developed optimized health area for the care needs of parents of children with cancer by using outcomes of FIN-PED II. The FIN-PED II can be provided to apply effective nursing interventions about carrying out care and unmet needs of parents of children with cancer.

\section{Conclusion}

To our knowledge, this is the first study to measure the Turkish version of FIN-PED II for psychometric qual- 
ity. The results show that the Turkish version of FINPED II has acceptable psychometric qualities, which suggests its applicability to assess the care needs of parents during their child's treatment for cancer in Turkey.

Peer-review: Externally peer-reviewed.

Conflict of Interest: No conflict of interest.

Financial Support: None declared.

Authorship contributions: Concept - H.B., A.A., L.M.; Design - H.B., A.A.; Supervision - H.B., A.A., L.M.; Materials - H.B., A.A.; Data collection \&/or processing - H.B., A.A.; Analysis and/or interpretation - H.B., A.A., L.M; Literature search - H.B., A.A.; Writing - H.B., A.A.; Critical review - H.B., A.A., L.M.

\section{References}

1. American Cancer Society. Cancer Facts\&Figures 2013. https://www.cancer.org/research/cancer-facts-statistics/all-cancer-facts-figures/cancer-facts-figures-2013. html. Accessed June 20, 2017.

2. Kutluk MT, Yeşilipek A. Turkish National Pediatric Cancer Registry 2002-2008 (Turkish Pediatric Oncology Group and Turkish Pediatric Hematology Society). J Clin Oncol 2013;31:15.

3. Popp JM, Conway M, Pantaleao A. Parents' Experience With Their Child's Cancer Diagnosis: Do Hopefulness, Family Functioning, and Perceptions of Care Matter?. J Pediatr Oncol Nurs 2015;32(4):253-60.

4. Benedetti GMDS, Garanhani ML, Sales CA. The treatment of childhood cancer: unveiling the experience of parents. Rev Lat Am Enfermagem 2014;22(3):425-31.

5. Williams PD, Williams KA, Williams AR. Parental caregiving of children with cancer and family impact, economic burden: Nursing perspectives. Issues Compr Pediatr Nurs 2014;37(1):39-60.

6. Kearney JA, Salley CG, Muriel AC. Standards of Psychosocial Care for Parents of Children With Cancer. Pediatric Blood \& Cancer 2015;62(S5):S632-S683.

7. Hocking MC, Kazak AE, Schneider S, Barkman D, Barakat LP, Deatrick JA. Parent perspectives on family-based psychosocial interventions in pediatric cancer: a mixed-methods approach. Support Care Cancer 2014;22(5):1287-94.
8. Monterosso L, Kristjanson LJ. Supportive and palliative care needs of families of children who die from cancer: an Australian study. Palliat Med 2008;22(1):59-69.

9. Arabiat DH, Altamimi A. Unmet care needs of parents of children with cancer in Jordan: implications for bed-side practice. Journal of Clinical Nursing 2013;22(3-4):531-9.

10. Soanes L, Hargrave D, Smith L, Gibson F. What are the experiences of the child with a brain tumour and their parents? Eur J Oncol Nurs 2009;13(4):255-61.

11. Monterosso L, Kristjanson LJ, Dadd G. Content validity and reliability testing of the FIN-PED II: A tool to measure care needs of parents of children with cancer. Journal of Nursing Measurement 2006;14(1):31-44.

12. Heckel L, Fennell KM, Reynolds J, Osborne RH, Chirgwin J, Botti M, et al. Unmet needs and depression among carers of people newly diagnosed with cancer. Eur J Cancer 2015;51(14):2049-57.

13. Arabiat DH, Hamdan-Mansour A, Al Jabery MA, Wardam L, Tamimi A. Measuring care needs of parents of children with cancer: Psychometric properties of the FIN-PED II Arabic version. Journal of nursing measurement 2015;23(2):255-70.

14. Whiteley EM, Kristjanson LJ, Degner LF, Yanofsky R, Mueller B. Measuring the care needs of mothers of children with cancer: Development of the FIN-PED. Canadian Journal of Nursing Research 1999;31(2):103-23.

15. Kerr LM, Harrison MB, Medves J, Tranmer JE, Fitch MI. Understanding the supportive care needs of parents of children with cancer: An approach to local needs assessment. Journal of Pediatric Oncology Nursing 2007;24(5):279-93.

16. Gibbins J, Steinhardt K, Beinart H. A systematic review of qualitative studies exploring the experience of parents whose child is diagnosed and treated for cancer. Journal of Pediatric Oncology Nursing 2012;29(5):253-71.

17. Maree JE, Parker S, Kaplan L, Oosthuizen J. The information needs of south african parents of children with cancer. Journal of Pediatric Oncology Nursing 2016;33(1):9-17.

18. Nightingale R, Friedl S, Swallow V. Parents' learning needs and preferences when sharing management of their child's long-term/chronic condition: a systematic review. Patient education and Counseling 2015;98(11):1329-38. 